\title{
IMPACTO DO CAPITAL SOCIAL NO PROCESSO DE FORMAÇÃO E EVOLUÇÃO DA ASSOCIAÇÃO DE UNIVERSIDADES DO GRUPO DE MONTEVIDÉU (AUGM)
}

\author{
THE IMPACT OF SOCIAL CAPITAL IN THE FORMATION AND \\ EVOLUTION PROCESS IN THE ASSOCIATION OF UNIVERSITIES \\ GRUPO MONTEVIDEO (AUGM)
}

\author{
Data de submissão: $17-08-2012$ \\ Aceite: $17-05-2014$ \\ Larissa Cristina Dal Piva Moreira ${ }^{1}$ \\ Sandro Aparecido Gonçalves²
}

\section{RESUMO}

Este trabalho trata do processo de formação e evolução de uma organização internacional em rede, a Associação de Universidades do Grupo de Montevidéu (AUGM), sob a perspectiva do capital social. A importância deste estudo de caso se justifica tanto pela possibilidade de analisar o desempenho organizacional sob a perspectiva sociológica do capital quanto pela escassez de pesquisas em torno dessa temática, especialmente por retratar aspectos do contexto latino-americano. Sob uma concepção epistemológica interpretativista, esta pesquisa parte de uma abordagem qualitativa, fazendo uso de técnicas de entrevistas focadas e de Análise de Redes Sociais (ARS) com o auxílio do software UCINET. Como resultado, observou-se que, por meio das interações na rede, foi possível estabelecer normas e expectativas para o desenvolvimento das atividades, com interpretações e informações partilhadas por canais apropriados. Dessa forma, em razão de um conjunto de ativos intangíveis desenvolvidos com base nas relações interpessoais mantidas entre os participantes da AUGM, esta foi institucionalizada tanto nas universidadesmembro como no meio internacional.

Palavras-chave: Capital social. Organização em rede. Internacionalização. Universidades.

\footnotetext{
1 Possui graduação em Comunicação Social - Relações Públicas pela Universidade Federal de Santa Maria, UFSM, graduação em Administração pela Universidade Federal de Santa Maria, UFSM, mestrado em Administração pela Universidade Federal do Paraná, UFPR e doutorado em andamento em Estudos Estratégicos Internacionais pela Universidade Federal do Rio Grande do Sul, UFRGS. Porto Alegre. Rio Grande do Sul. Brasil. E-mail: laridalpiva@gmail.com

2 Possui graduação em Ciências Contábeis pela Universidade de São Paulo, USP, mestrado em Administração pela Universidade Federal do Paraná, UFPR e doutorado em Administração de Empresas pela Fundação Getúlio Vargas - SP, FGV-SP. Curitiba. Paraná. Brasil. E-mail: sag2@ uol.com.br
} 


\section{ABSTRACT}

This paper brings the process of formation and evolution of an international network organization, the Association of Universities Grupo Montevideo (AUGM), from the perspective of social capital. The importance of this study is justified both by the rarity in the Latin American context and by the fact that analyses the organizational performance from a sociological perspective of capital. Under an interpretive epistemological concept, it was developed a qualitative approach with case study method and techniques of focused interviews and analysis of social networks with UCINET software. It was observed that, through the network interaction, it could be established standards and expectations for the development of activities, with interpretations and information shared by appropriate canals. Thus, due to a set of intangible assets developed based on interpersonal relationships maintained in the organizational network, the AUGM was institutionalized at universities members and in the international environment.

Keywords: Social capital. Network organization. Internationalization. University.

\section{INTRODUÇÃO}

Redes, estruturas de cooperação e novos marcos de integração entre as instituições trazem novos paradigmas nas formas de interação organizacional, tanto no nível dos fenômenos quanto nas abordagens conceituais. Assim, é plausível considerar a necessidade de estudar o capital social envolvido nessas relações, na medida em que este exerce influência sobre as razões paraa formação e a evolução da rede.

De acordo com Lin (2001) e Nahapiet e Goshal (1998), o capital social em suas distintas dimensões influencia a forma de interação nas redes, porque facilita o fluxo de informação, exercendo interferência nos agentes, além de apresentar credenciais sociais e reforçar a identidade e o reconhecimento dos atores da rede. Pode-se afirmar, assim, que "diz respeito a características da organização social como confiança, normas e sistemas que contribuam para aumentar a eficiência da sociedade, facilitando as ações coordenadas" (PUTNAM, 2000, p. 177).

Tendo isso em vista, este texto se fundamenta em teorias de capital social e de redes aplicada às organizações, para estudar como o capital social contribuiu ao longo do tempo para a formação, evolução e configuração de uma organização internacional em forma de rede, a Associação de Universidades do Grupo de Montevidéu (AUGM). Como se tornará evidente, trata-se, contudo, de algo que vai além de uma rede organizacional: a AUGM consiste, na verdade, em uma organização em rede.

\section{FUNDAMENTOS TEÓRICOS}

\subsection{Capital social e organizações em rede}

Bourdieu (1986, p. 51) define o capital social como um "conjunto de recursos atuais ou potenciais que estão ligados à posse de uma rede de relações mais ou menos institucionalizadas de conhecimento mútuo e reconhecimento". Nesta definição, é possível distinguir os elementos constitutivos do capital social: as relações sociais que permitem ao indivíduo obter recursos da rede e a qualidade e quantidade desses recursos.

Sob um enfoque do capital social como um bem público e das pessoas, Coleman (1988, p. 98) afirma que o mesmo é "definido pelas suas funções, não se apresentando como uma entidade única, mas como diversas entidades distintas, com dois elementos em comum: todos consistem de alguns aspectos das estruturas sociais e facilitam certas ações dos atores dentro destas estruturas". Para o autor, o capital social só existe na relação entre os atores sociais, ao contrário dos capitais econômico 
e intelectual, que podem ser propriedades do indivíduo. Nesse sentido, este tipo de capital não é um atributo dos indivíduos, mas um aspecto dependente do contexto e da estrutura social, ou seja, inerente à estrutura das relações entre dois ou vários atores. O capital social não está nos próprios atores nem nos instrumentos físicos de produção, de modo que sua aquisição só ocorre "por meio de mudanças nas relações entre as pessoas, o que facilita a ação" (COLEMAN, 1988, p. 100).

Tanto para Portes (1998) quanto para Bourdieu (1986), o capital social assume formas mais instrumentais, pois consideram que as pessoas constroem suas relações levando em conta os benefícios que obteriam posteriormente. Esse pensamento diverge da posição de Coleman (1988) e de Putnam (2000), para quem o capital social é um bem público da sociedade.

No que diz respeito às redes organizacionais, autores como Granoveter (1992), Burt (1992) e Lin (2001) demonstram um entendimento próximo do de Bourdieu (1986), avaliando o capital social na rede com foco na utilidade para os seus membros.

Granovetter (1973) trata de aspectos mais específicos da estrutura do capital social, destacando a força dos laços fracos, já que são as relações de não parentesco que importam para a expansão de uma rede. Para esse autor, a força dos laços depende da combinação entre quantidade de tempo, intensidade emocional, intimidade (confiança mútua) e serviços de reciprocidade que caracterizam um laço.

Para entender como as relações sociais incidem no comportamento econômico e nas instituições que o regulam, Granovetter (1992) elabora o conceito de embeddedness (imbricação ou imersão, conforme o contexto), defendendo que os atores, sejam eles pessoas ou organizações, perseguem objetivos econômicos e sociais. Para tanto, não atuam de forma isolada ou autônoma, pois as suas ações econômicas estão imbricadas (embeddedness) em uma rede de relações sociais.

Nessa mesma linha de pensamento, Burt (1992) sustenta que o capital social pode ser formado a partir de redes, por meio das quais os atores podem intermediar conexões entre diferentes segmentos desconectados, enfatizando os laços fracos entre eles como fonte de capital social. Dessa forma, o autor afirma que, em redes abertas (definidas como buracos estruturais), os membros têm mais independência para explorar informações menos redundantes. Esses buracos estruturais não significam que um grupo não percebe a existência do outro, mas que cada grupo está focado em atividades diferentes.

Burt (1992) ressalta, ainda, a importância da confiança e da reciprocidade para a eficiência das redes. A confiança presente nas relações entre os atores contribui para a manutenção dos vínculos sociais e para o controle de comportamentos oportunistas e indesejados coletivamente. Nesse sentido, a confiança passa a ser preditora da conduta dos atores, requerendo, para tanto, a existência de normas de reciprocidade e de respeito mútuo. Assim, na visão do autor, a reciprocidade seria a norma mais relevante em termos de capital social.

Estas e outras características do capital social foram classificadas, de acordo com Nahapiet e Goshal (1998), em três dimensões: 1) dimensão estrutural, que se refere ao padrão de conexão entre os atores, incluindo as conexões e configurações da rede que descrevem o padrão de ligações em termos de mensuração como densidade, conectividade, hierarquia e adequação organizacional; 2) dimensão relacional, referindo-se aos ativos que são criados e alavancados por meio do relacionamento e incluem atributos como identificação, confiança, normas, sanções, obrigações e expectativas; e 3) dimensão cognitiva, que diz respeito aos recursos que representam visões compartilhadas, interpretações e sistemas de significados, abrangendo, por exemplo, a linguagem, os códigos e as narrativas.

Como complemento, Koka e Prescott (2002) identificam a dimensão informacional do capital social, que engloba o volume, a diversidade e a riqueza das informações. Quanto mais vínculos existirem em uma organização, maiores serão o volume e a troca de informações, pro- 
porcionando mais oportunidades de aprendizagem, de geração de novos conhecimentos e de construção de compromissos mútuos.

Os conceitos de capital social, bem como seus elementos constitutivos e suas formas de aquisição e compartilhamento, são apresentados resumidamente no Quadro 1 a seguir.

\begin{tabular}{|c|c|c|}
\hline Autor & Elementos constitutivos & Aquisição e compartilhamento \\
\hline Bourdieu (1986) & $\begin{array}{l}\text { Relações sociais para obter recursos; } \\
\text { Qualidade e quantidade de recursos }\end{array}$ & $\begin{array}{l}\text { Habituação a normas, lealdade, hones- } \\
\text { tidade e interligação ao grupo; } \\
\text { Sociabilidade e "favores"; } \\
\text { Distribuição desigual }\end{array}$ \\
\hline Coleman (1988) & $\begin{array}{l}\text { Aspectos das estruturas sociais; } \\
\text { Ações dos atores dentro das estruturas } \\
\text { sociais }\end{array}$ & $\begin{array}{l}\text { Mudanças nas relações entre os atores } \\
\text { que facilitam as ações dentro das estru- } \\
\text { turas sociais }\end{array}$ \\
\hline Putnam (1990) & Confiança, normas e sistemas & $\begin{array}{l}\text { Teoria dos jogos; } \\
\text { Reciprocidade }\end{array}$ \\
\hline Granoveter (1992) & $\begin{array}{l}\text { Quantidade de tempo; } \\
\text { Intensidade emocional; } \\
\text { Intimidade (confiança mútua); } \\
\text { Reciprocidade }\end{array}$ & $\begin{array}{l}\text { Embeddedness; } \\
\text { Laços fortes e fracos }\end{array}$ \\
\hline Burt (1992) & $\begin{array}{l}\text { Laços fracos e fortes; } \\
\text { Confiança e reciprocidade }\end{array}$ & $\begin{array}{l}\text { Habilidade dos atores em construir elos } \\
\text { entre atores desconectados (buracos } \\
\text { estruturais) }\end{array}$ \\
\hline $\begin{array}{l}\text { Nahapiet e Goshal } \\
\text { (1998) }\end{array}$ & $\begin{array}{l}\text { Recursos atuais e potenciais derivados } \\
\text { de redes de relacionamento }\end{array}$ & $\begin{array}{l}\text { Três dimensões: estrutural, relacional e } \\
\text { cognitiva }\end{array}$ \\
\hline $\operatorname{Lin}(2001)$ & $\begin{array}{l}\text { Posição estrutural; } \\
\text { Acessibilidade aos recursos; } \\
\text { Efeitos da ação }\end{array}$ & $\begin{array}{l}\text { Recursos acessados e mobilizados por } \\
\text { meio dos laços na rede; } \\
\text { Informação, influência e credencial so- } \\
\text { cial }\end{array}$ \\
\hline
\end{tabular}

Quadro 1: Elementos constitutivos, aquisição e compartilhamento de capital social. Fonte: elaboração própria.

Feitas essas considerações, é possível definir o capital social como a soma dos recursos atuais e potenciais derivados de redes de relacionamento mantidas por um indivíduo ou uma unidade social (NAHAPIET; GOSHAL, 1998) que resultam em valores e normas dos relacionamentos, permitindo a cooperação dentre ou entre os diferentes grupos sociais (MARTELETO; SILVA, 2004). É, assim, um conjunto de ativos intangíveis, desenvolvido com base nas relações interpessoais mantidas na organização.

\subsection{Configuração de redes e Análise de Redes Sociais}

A utilização de técnicas de Análise de Redes Sociais (ARS) em organizações significa a busca por explicações contextuais e sistêmicas que substituam as individualistas e atômicas (BORGATTI; FOSTER, 2003). Dessa forma, é possível estudar a configuração da rede organizacional, bem como compreender as ligações entre entidades sociais e as implicações destas ligações (WASSERMAN; FAUST, 1994).

Na última década, a ARS tem sido utilizada para analisar organizações, uma vez que a rede social em organizações cria um grupo de pessoas, equipes ou empresas, interligadas por relações sociais, trocando conhecimento e informações necessárias à realização de seu trabalho. Assim, analisar essas redes significa criar modelos e métodos que permitam visualizar e medir os padrões de comportamentos destas comunidades (BORGATTI; FOSTER, 2003).

De acordo com Wasserman e Faust (1994), a ARS é baseada nas seguintes premissas:

a) os atores e suas ações são vistas como interdependentes, e cada ator é uma unidade autônoma; 
b) as relações entre atores são canais que transferem recursos, podendo ser materiais ou imateriais;

c) os modelos de redes focam visões individuais do meio estrutural de rede, proporcionando oportunidades para as restrições sobre ações individuais;

d) os modelos de redes conceituam estruturas sociais, econômicas ou outras como os últimos padrões de relações entre os atores.

Wasserman e Faust (1994) apresentam, ainda, quatro elementos fundamentais à análise de redes: os nós, as posições, as ligações e os fluxos. Os nós podem ser definidos como os pontos ou atores que compõem a rede; as posições definem as localizações dos pontos no interior de uma estrutura; as ligações ou conexões determinam o grau de densidade ou de difusão dos atores da rede; es fluxos, tangíveis ou intangíveis, indicam a troca de recursos, informações, bens, serviços e contatos.

Para esses mesmos autores, algumas medidas estruturais são básicas na análise de redes: tamanho, densidade, distância geodésica e coesão. $O$ tamanho diz respeito ao número de atores que compõem a rede; a densidade indica a quantidade de relações entre os atores; a distância geodésica refere-se à quantidade média de ligações necessárias para o estabelecimento de uma relação com qualquer ator da rede; e a coesão informa sobre a existência de subgrupos na rede.

Essas medidas possibilitam análises mais aprofundadas sobre outros aspectos de uma rede, como a centralidade dos atores. A centralidade pode ser considerada a posição de um ator na rede em relação aos demais, sendo mensurada pela quantidade de elos que se colocam entre os atores da rede (WASSERMAN; FAUST, 1994).

Dessa forma, a medida de centralidade permite conhecer a posição dos nós no interior da rede, bem como entender a estrutura da própria rede. De acordo com Wasserman e Faust (1994), a posição do ator na rede pode ser analisada segundo três critérios:

a) grau de centralidade (degree centrality) - mede o número de laços de um ator, ou seja, com quantos outros atores pertencentes à rede ele está conectado;

b) grau de intermediação (betweenness) - mede a frequência com que um ator serve de conexão entre outros dois atores não adjacentes da mesma rede;

c) grau de proximidade (closeness) - indica o quanto um ator está próximo de outros atores integrantes da rede.

Ao contrário da densidade, as especificidades de qualquer rede também podem ser avaliadas em termos de buracos estruturais existentes, ou seja, dos espaços vazios na estrutura da rede que indicam a ausência de relações entre determinados atores ou grupos. Para Wasserman e Faust (1994), essas medidas permitem verificar até que ponto uma rede pode alcançar todo o seu potencial. Quanto maior for o número de laços em uma rede, maior será o seu potencial.

De forma resumida e esquemática, essas medidas estruturais podem ser observadas via três níveis de análise das características de uma rede social: rede como um todo, laços da rede e papel de cada ator (WASSERMAN; FAUST, 1994; SCOTT, 2000; MONGE; CONTRACTOR, 2001; HANNEMAN, 2005):

$\mathrm{Na}$ análise da rede como um todo, são avaliadas métricas que dizem respeito à estrutura da rede e ao grau de interação e coesão entre seus componentes. As principais métricas utilizadas são:

a) tamanho - mede o total de atores e ligações. Quanto maior for uma rede, mais difícil será conhecer os outros e trocar informações;

b) densidade - mede a relação entre o total de ligações existentes e o total de ligações possíveis. Valores baixos podem indicar oportunidades de maior colaboração; 
c) simetria - mensura a relação entre o número de laços simétricos e assimétricos;

d) centralização - avalia a diferença entre os escores de centralidade do ator mais central e de todos os outros atores em uma rede.

Já a caracterização do tipo de laço de relacionamento que há entre os atores dentro da rede está embasa na análise da frequência de quantas vezes o laço ocorre; da estabilidade do laço ao longo do tempo; da força, ou seja, da quantidade de tempo, intensidade emocional, intimidade e serviços recíprocos; da direção dos laços entre os atores; e da simetria dos laços (MONGE; CONTRACTOR, 2001).

O último nível de análise estuda a rede de um ator específico, também chamada de rede egocêntrica. Para isso, avaliam-se o ator e as ligações com seus vizinhos, buscando entender a influência do grupo sobre o indivíduo, isto é, de que forma o grupo impõe limites ou promove oportunidades.

Ao identificar a influência que cada membro exerce na manutenção e na expansão da rede, é possível classificá-lo em:

a) estrela (star) - ator é central na rede;

b) ligação (liaison) - ator tem ligações com dois ou mais grupos que não estariam ligados, mas não é um membro de nenhum grupo;

c) ponte (bridge) - ator é membro de dois ou mais grupos;

d) porteiro (gatekeeper) - ator que controla o fluxo (é a única ligação) entre uma parte da rede e outra;

e) isolado - ator que não tem ou tem poucas ligações.

Para finalizar, ressalta-se que a ARS pode ser mais útil para grandes organizações geograficamente dispersas, onde a comunicação virtual é mais comum que a presencial. Neste trabalho, a configuração da rede será analisada juntamente com o capital social da Associação de Universidades do Grupo Montevidéu (AUGM), que é uma rede internacional englobando universidades de seis países da América do Sul.

\section{PROCEDIMENTOS METODOLÓGICOS}

Partindo-se do pressuposto de que a motivação para criação ou participação em uma organização em rede nem sempre é dada por razões econômicas, mas também por laços de afetividade e confiança entre os membros, este trabalho assume uma concepção epistemológica interpretativista. Apresenta, assim, uma abordagem qualitativa com método de estudo de caso e técnicas de entrevistas focadas (GODOI, 2006) e Análise de Redes Sociais (ARS) (WASSERMAN; FAUST, 1994).

Fundada em 1991, a Associação de Universidades do Grupo de Montevidéu (AUGM) é uma organização em rede, composta de 28 universidades públicas, com o objetivo de promover integração acadêmica, intercâmbios, parcerias e cooperação técnica na América do Sul, incluindo o Brasil, a Bolívia, a Argentina, o Chile, o Paraguai e o Uruguai. É o único caso de organização em rede bem-sucedido na região.

Para alcançar o objetivo geral de analisar como o capital social influenciou a configuração da AUGM, primeiramente foi realizado o mapeamento da rede no período de 1991 a 2011. Utilizaram-se dados secundários, como documentos históricos (atas de reuniões) e o livro de 15 anos da organização, e entrevistas com os membros da rede ao longo deste período, envolvendo desde a cúpula organizacional, formada por Reitores e Delegados Assessores, até professores e alunos intercambistas das universidades-membro, sendo importante destacar que todas foram coletadas in loco em cada país envolvido. 
Dessa forma, por meio das informações obtidas acerca da relação existente entre as universidades-membro, foi realizado o mapeamento da rede AUGM com cortes transversais na perspectiva longitudinal em três distintos períodos selecionados aleatoriamente: 1991 - momento de fundação da organização; 2001- momento intermediário; e 2011- momento de encerramento da pesquisa de campo.

Estas relações entre os membros foram analisadas pelo software UCINET (BORGATTI et al., 2002), utilizando três indicadores previamente selecionados: densidade, centralidade e simetria. $O$ indicador densidade foi computado medindo a proporção entre os laços presentes e o número total de laços possíveis, excluindo os laços que aparecessem na intersecção do ator com ele mesmo. $O$ indicador centralidade, por sua vez, foi analisado por meio de medidas de centralidade (degree), avaliando o prestígio do ator pelo número de laços de entrada (indegree) e pelo número de laços de saída (outdegree). Já a simetria foi observada nos movimentos entre pontos correlativos.

A ARS permitiu visualizar e mensurar os padrões de comportamentos da estrutura da rede AUGM em três níveis de análise: rede como um todo; laços da rede; e papel de cada ator (MONGE; CONTRACTOR, 2001):

a) rede com um todo - nesta análise, foram avaliadas métricas que dizem respeito à estrutura da rede e ao grau de interação e coesão entre seus componentes, como tamanho, densidade, simetria e centralização;

b) laços da rede - consistiu na caracterização do tipo de laço de relacionamento que há entre os atores dentro da rede, sendo embasada na análise da frequência de quantas vezes o laço ocorre; da estabilidade do laço ao longo do tempo; da força, ou seja, da quantidade de tempo, intensidade emocional, intimidade e serviços recíprocos; da direção dos laços entre os atores; e da simetria das relações;

c) papel de cada ator - observou-se a rede de um ator específico, avaliando as ligações com seus vizinhos, para entender a influência do grupo sobre o indivíduo e de que forma o grupo impõe limites ou promove oportunidades. Ao identificar a influência que cada membro exerce na manutenção e na expansão da rede, os membros puderam ser classificados em: estrela (ator central); ligação (tem ligações com grupos que não estariam ligados, mas não é membro de nenhum grupo); ponte (membro de dois ou mais grupos); porteiro (única ligação entre duas partes da rede); e isolado.

Com base no conteúdo das entrevistas e no mapa da rede gerado pelo UCINET, o capital social foi analisado em suas dimensões estrutural, relacional, cognitiva e informacional (NAHAPIET; GOSHAL, 1998; KOKA; PRESCOTT, 2002). A dimensão estrutural foi analisada conjuntamente com o mapeamento da rede AUGM por meio de ferramentas de ARS, surgindo, então, a necessidade de três indicadores para as demais dimensões do capital social: confiança e reciprocidade (dimensão relacional) e canais de comunicação (dimensão cognitiva e informacional).

Ressalta-se que as ligações do UCINET ilustram a rede organizacional AUGM. Contudo, optou-se por construir a rede pelo critério de presença ou ausência do laço, não sendo possível avaliar a intensidade deste, em detrimento da utilização da escala Likert.

A análise das dimensões do capital social, correlacionando os conceitos de Nahapiet e Goshal (1998) e Koka e Prescott (2002), pode ser percebida por meio dos indicadores e das questões de pesquisa apresentadas no Quadro 2. 


\begin{tabular}{|c|c|c|c|c|}
\hline Dimensão & Estrutural & Relacional & Cognitiva & Informacional \\
\hline Conceito & $\begin{array}{l}\text { Padrão de conexão } \\
\text { entre os atores e } \\
\text { conexões e confi- } \\
\text { gurações da rede }\end{array}$ & $\begin{array}{c}\text { Ativos que são cria- } \\
\text { dos e alavancados } \\
\text { por meio do relacio- } \\
\text { namento }\end{array}$ & $\begin{array}{l}\text { Recursos que re- } \\
\text { presentam visões } \\
\text { compartilhadas }\end{array}$ & $\begin{array}{l}\text { Volume, diversi- } \\
\text { dade e riqueza } \\
\text { das informações }\end{array}$ \\
\hline Indicadores & $\begin{array}{c}\text { Densidade, conec- } \\
\text { tividade e hierar- } \\
\text { quia }\end{array}$ & $\begin{array}{l}\text { Identificação, con- } \\
\text { fiança, normas, obri- } \\
\text { gações, sanções e } \\
\text { expectativas }\end{array}$ & $\begin{array}{c}\text { Linguagem, códigos } \\
\text { e narrativas }\end{array}$ & $\begin{array}{c}\text { Quantidade e } \\
\text { qualidade dos } \\
\text { canais de comuni- } \\
\text { cação, emissor e } \\
\text { receptor }\end{array}$ \\
\hline $\begin{array}{l}\text { Questões de pes- } \\
\text { quisa }\end{array}$ & $\begin{array}{l}\text { 1- Quais são os } \\
\text { participantes da } \\
\text { rede? } \\
\text { 2- Qual é a frequ- } \\
\text { ência de interação } \\
\text { entre eles? } \\
\text { 3- Existe hierar- } \\
\text { quia interna na } \\
\text { rede? }\end{array}$ & $\begin{array}{l}\text { 1- Há participação de } \\
\text { todos os membros da } \\
\text { rede? } \\
\text { 2- Existe confiança e } \\
\text { reciprocidade entre } \\
\text { Os membros? } \\
\text { 3- Os membros se- } \\
\text { guem normas da } \\
\text { rede? } \\
\text { 4- Há restrições ou } \\
\text { obrigações internas } \\
\text { na rede? } \\
\text { 5- Há autonomia } \\
\text { para entrar e sair da } \\
\text { rede? } \\
\text { 6- Os membros par- } \\
\text { ticipam da rede por } \\
\text { quais motivações? }\end{array}$ & $\begin{array}{l}\text { 1-A informação } \\
\text { é compartilhada } \\
\text { frequentemente e } \\
\text { de forma formal ou } \\
\text { informal? } \\
\text { 2- Qual linguagem } \\
\text { e qual canal de } \\
\text { comunicação são } \\
\text { mais utilizados en- } \\
\text { tre os membros da } \\
\text { rede? } \\
\text { 3- Qual é o conteú- } \\
\text { do da comunicação } \\
\text { interna da rede? }\end{array}$ & $\begin{array}{c}\text { 1- Quais são os } \\
\text { veículos de comu- } \\
\text { nicação utilizados } \\
\text { na rede AUGM? } \\
\text { 2- O que se trans- } \\
\text { mite pelos canais } \\
\text { de comunicação } \\
\text { da AUGM? } \\
\text { 3- Quem são os } \\
\text { principais emisso- } \\
\text { res e receptores } \\
\text { de comunicação } \\
\text { na rede AUGM? }\end{array}$ \\
\hline
\end{tabular}

Quadro 2: Análise das dimensões do capital social. Fonte: adaptado de Nahapiet e Goshal (1998) e Koka e Prescott (2002).

\section{INTERPRETAÇÃO E ANÁLISE DOS DADOS}

O contexto histórico e socioeconômico no início da década de 1990 envolve questões vinculadas à globalização e influências de caráter neoliberal. Em 1991, foi assinado o Tratado de Assunção entre Argentina, Brasil, Paraguai e Uruguai, que deu origem ao Mercado Comum do Sul (Mercosul). Visando à integração e ao desenvolvimento regional, oito Reitores de universidades públicas do Mercosul começaram um processo político-acadêmico até então inédito na vida universitária da região: a criação da Associação de Universidades do Grupo de Montevidéu (AUGM).

Desde sua fundação, a AUGM recebe influência do capital social resultante das relações pessoais, e, com o passar do tempo, este fator assume um caráter coletivo e próprio da organização. A reunião para a formação da AUGM, ocorrida na capital do Uruguai, contou com a presença de oito Reitores de universidades de quatro países (Argentina, Brasil, Uruguai e Paraguai). É observável aí o primeiro impacto do capital social, visto que cada Reitor se fez presente neste encontro por convite de algum outro Reitor conhecido. O mapa da rede em 1991 foi construído no UCINET e pode ser visualizado na Figura 1, exposta a seguir. 


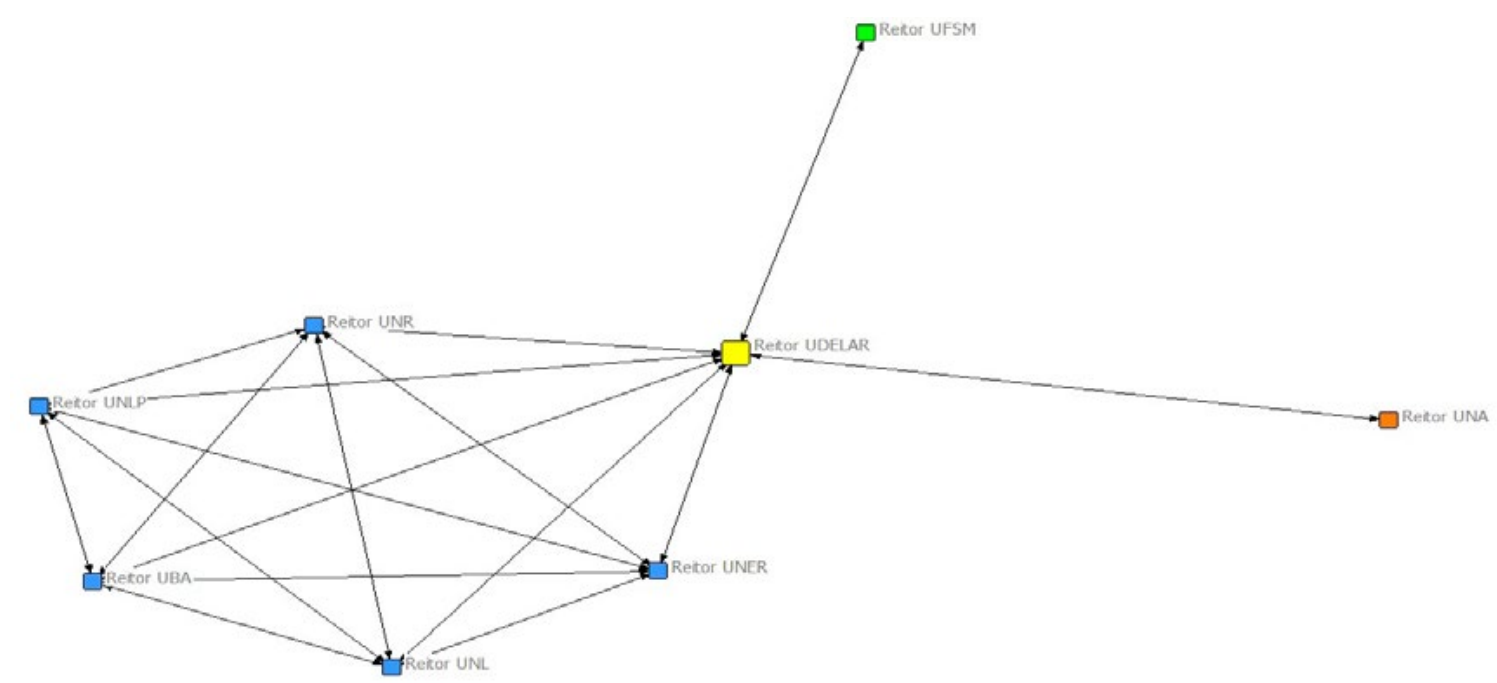

Figura 1: Mapa da rede AUGM em 1991. Fonte: elaborado a partir dos dados da pesquisa.

Montevidéu (Uruguai) foi escolhido como sede do primeiro encontro, "porque basta o Reitor da Universidad de la República (UDELAR) atravessar a rua que está no Palácio do Governo ou na sede da UNESCO", conforme relatou um dos entrevistados, o que explica o papel de estrela e porteiro exercidos pelo Reitor da UDELAR na rede.

Analisando ainda a dimensão estrutural, observa-se que a densidade, relativa ao índice de conectividade dos membros na rede, é de $60,07 \%$, significando que existe este número de laços em relação ao total de conexões possíveis. Quanto à simetria, o fato de os laços serem bidirecionais faz com que a rede seja simétrica. Quanto à centralidade da rede, de acordo com a medida de grau (Freeman's degree centrality measures), o número de laços que entram (indegree) e que saem (outdegree) é o mesmo, totalizando $44,89 \%$ de centralização da rede. Em relação à medida de proximidade (closseness), a rede está 62,96\% centralizada.

A dimensão relacional do capital social pode ser observada em função da relação dos laços na rede. Como a frequência dos encontros ainda não estava estabelecida, no momento de formação da rede, não havia estabilidade. As comunicações eram bidirecionais e recíprocas, mas o fluxo informacional não era ágil porque não havia conexão entre todos os membros da rede.

Dentro da dimensão relacional, constata-se a confiança, cuja existência é percebida pelo fato de os Reitores já se conhecerem e terem a vontade comum de fundar uma associação juntos. Entretanto, para evitar oportunismos e legalizar a situação, foi feita uma ata de fundação, caracterizando uma primeira norma e formalização da rede.

Quanto à dimensão cognitiva do capital social na rede, percebe-se que o objetivo compartilhado de desejo de integração e fortalecimento da educação pública na América do Sul fez com que os membros superassem com êxito as diferenças linguísticas entre o português e o espanhol.

Em relação à dimensão informacional do capital social na época de fundação da AUGM, a distância geográfica e a inexistência de tecnologias de informação como a internet fizeram com que as comunicações fossem por carta ou telefone, demandando certo tempo e dispêndio monetário. Acredita-se que, por isso, a diversidade, a riqueza e o volume de informações na época fossem muito pequenos em relação à atualidade. Entre 1992 e 2001, a AUGM formalizou-se, com a criação de uma sede executiva para o controle de novas atividades e programas, instaurando, por exemplo, o encontro dos comitês acadêmicos e núcleos disciplinares para trabalho em conjunto entre professores e alunos das universidades-membro e o Programa ESCALA de Mobilidade Acadêmica que começou em 2000. 
Com estes projetos em andamento, o estatuto da organização sofreu mudanças: o Secretário Executivo já não necessitava ser o Reitor de uma das universidades-membro, permanecendo no cargo o ex-Reitor da UDELAR. Por outro lado, os novos membros deveriam ser convidados após decisão em uma reunião do Conselho de Reitores. Dessa forma, o capital social interpessoal tem possibilidade de expansão ao longo da rede, amenizando-se as influências pessoais dos fundadores, que em sua maioria já não exerciam o cargo de Reitor ou não estavam presentes nas universidades-membro. O mapa da rede em 2001 pode ser observado na Figura 2.

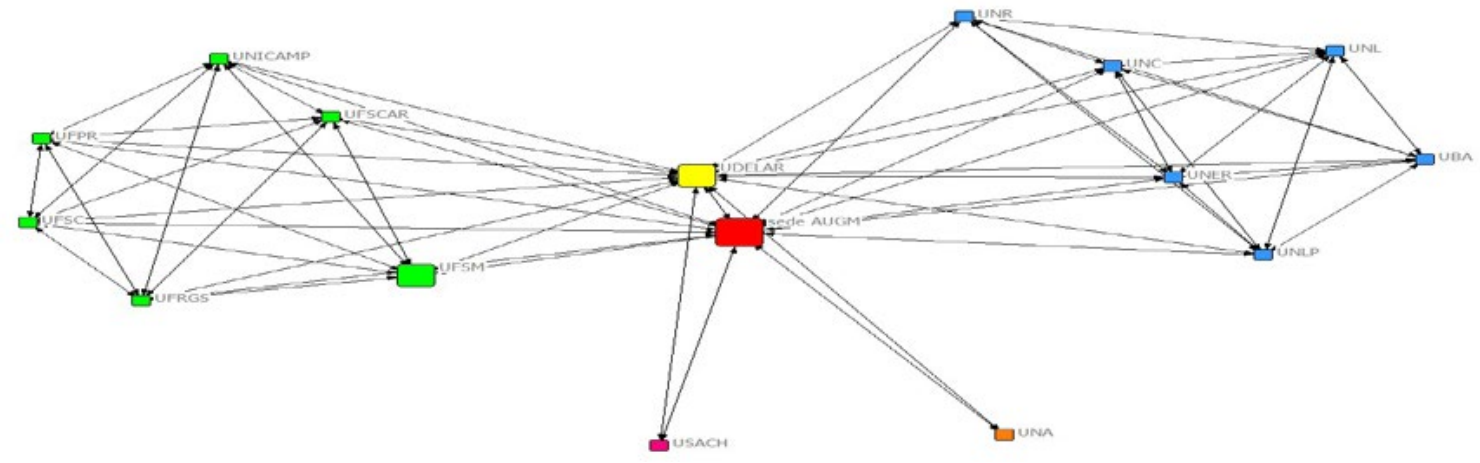

Figura 2: Mapa da rede AUGM em 2001. Fonte: elaborado a partir dos dados da pesquisa

Nesse segundo período escolhido para análise, no que diz respeito à dimensão estrutural do capital social, observou-se que, com o aumento dos membros, houve uma dispersão dos laços na rede. A densidade, de 49,17\%, significa que existe este número de laços em relação ao total de conexões possíveis, indicando um decréscimo em relação ao período anterior.

Quanto à centralidade e ao papel dos atores, percebe-se que, juntamente com o Reitor da UDELAR, a sede da AUGM também obtém destaque com grande número de conexões outdegree (laços de entrada) e indegree (laços de saída). Estes dois nós são os mais centrais na rede por terem mais laços, sendo maior a capacidade de acessar, direta ou indiretamente, outros atores na rede. Por outro lado, notaram-se alguns nós mais isolados, como é o caso da Universidade Nacional de Asunción (UNA) e da Universidade de Santiago do Chile (USACH). Estas são as únicas universidades-membro de seus países, Paraguai e Chile, o que justifica essa posição e faz com que, apesar de sua baixa centralidade e de serem periféricos na rede, não sejam removidos e ainda tenham efeitos significativos na rede.

Em entrevista realizada na Secretaria Executiva da AUGM, revela-se outra faceta da rede: a equiparação entre o número de universidades-membro da Argentina e do Brasil. O número de membros dos dois países deve ser igual para que, sendo ambos grandes e de maior influência na América do Sul, um não tenha maior poder de voto que o outro dentro da organização. Nesse sentido, além da dimensão estrutural do capital social, englobando a densidade e a simetria da rede, deve-se levar em conta a dimensão relacional, que envolve questões ligadas ao poder, à identificação, à confiança, às normas e às expectativas.

No que diz respeito à dimensão relacional, há um aumento na frequência e na estabilidade dos laços em função das atividades programadas. Além disso, algumas organizações foram formalizando sua participação na AUGM, como é o caso da Universidade Federal de Santa Maria (UFSM), ao realizar a I Jornada de Jovens Pesquisadores em 1993. Entretanto, questões relativas às conexões estritamente pessoais ainda permaneciam na rede, como revela o discurso do Reitor da UFSM de 1994 a 1997 no livro comemorativo de quinze anos da AUGM: 
[...] a primeira impressão foi de um clube de amigos. Tal a harmonia e companheirismo que encontrei entre os Reitores das Universidades que compunham a AUGM quando a eles me juntei em 1994, como Reitor recém empossado da UFSM. A convivência me mostrou que além da amizade havia intenção proposta e institucionalizada no grupo. Os valores da excelência científica, da integração latino-americana e a consciência da educação como bem maior da cidadania, sempre pontificariam nas ações da AUGM. O papel desempenhado pela AUGM no fortalecimento dos laços de integração entre as nações do Cone Sul tem sido marcante ao longo da última década. Como toda a boa causa, o êxito da AUGM se deve sem dúvida ao engajamento da comunidade acadêmica das instituições parceiras (AUGM, 2006, p. 89, grifo nosso).

Em relação às dimensões cognitiva e informacional, com o desenvolvimento do computador e de novas tecnologias de informação, houve um aprimoramento nos canais de comunicação envolvendo computador e internet, o que fez com que a diversidade, a riqueza e o volume de informações trocadas entre os membros aumentassem. Entre 2009 e 2010, ocorreram mudanças no estatuto e na estrutura da organização: o cargo de Presidente de AUGM é assumido pelo Reitor de uma universidade-membro durante um ano, e foram convidadas mais dez universidades para se tornarem membros.

Nota-se aqui uma atenção maior à dimensão estrutural da rede, com a ampliação de membros, totalizando 28 universidades de seis países da América do Sul. O mapa da rede do ano de 2011 pode ser visualizado na Figura 3, exposta a seguir.

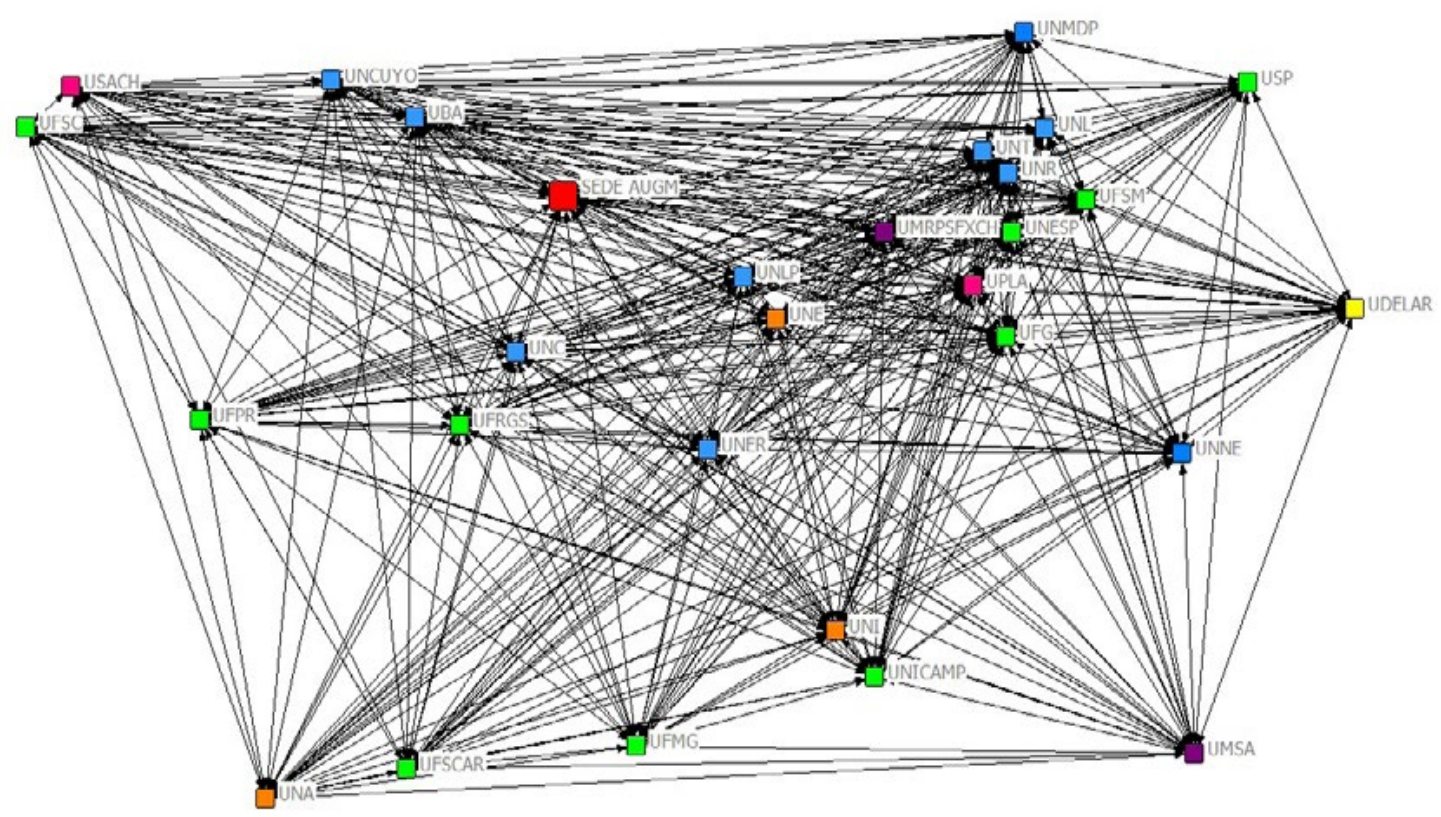

Figura 3: Mapa da rede AUGM em 2011. Fonte: elaborado a partir de dados da pesquisa.

Quanto à dimensão estrutural do capital social da AUGM, após 20 anos de fundação, a rede tornou-se mais densa com grande conectividade (100\%) e baixa centralidade $(0 \%)$, sem a presença de um ator central exercendo o papel de estrela ou de porteiro, como ocorria antes com a UDELAR e a sede da AUGM. A sede da AUGM exerce mais um papel de mediadora de conflitos e representante da rede do que de gestora única dos programas e das atividades, definindo-se, assim, seu papel como organização em rede. Cabe aqui referenciar o depoimento da coordenadora de Programas e Projetos da AUGM sobre o funcionamento da Secretaria Executiva da sede: 
[...] a AUGM tem uma Secretaria Executiva, que tem uma área técnica, que faz os programas serem desenvolvidos e se apoia em comissões que trabalham os temas. Assim, a AUGM planeja toda a arquitetura do programa e dá segmento para o programa ser operacionalizado pelas e nas universidades. São as universidades que convocam e recebem estudantes e docentes. Em geral, quando surge uma ideia para gerar um programa (como o Programa de Mobilidade para estudantes de pós-graduação), se forma uma comissão composta por um delegado de cada universidade. Essa é uma clássica forma de funcionamento da AUGM, que é através de comissões, grupos de trabalho, que são pessoas representantes de universidades que se reúnem para trocar ideias e sugestões para construir algo como uma política, um programa e para avaliar.

A dimensão estrutural da AUGM apresentou um fluxo de informações crescente entre os atores como a forma de uma curva de incrementos marginais decrescentes, o que está de acordo com Coleman (1988). A despeito de uma sede para a rede organizacional, os membros adquiriram forte conexão entre si, diminuindo a centralização estrutural do capital social e gerando diferenciação entre a capacidade da rede, em termos de trocas e diversidade de trocas, e a sua gestão. Tal fator tornou evidente a configuração de organização em rede.

Ressalta-se que, apesar de este resultado parecer contrário ao que se espera quando um grupo se torna maior, pois a proporção de todos os laços que podem logicamente estar presentes (densidade) deveria cair, dando espaço a grupos internos à rede, a alta conectividade pode ser devida às distintas atividades existentes na AUGM que obrigam o relacionamento entre os membros da rede, como é o caso do Programa ESCALA de Mobilidade Acadêmica, em que cabe às universidades-membro abrirem vagas em seus cursos de interesse para intercâmbio e receber alunos do mesmo curso de outras universidades. Isso pode ser percebido no depoimento de um aluno intercambista do curso de Letras da USACH que estudou no segundo semestre de 2011 o mesmo curso na Universidade Federal do Paraná (UFPR): "Eu vim estudar na UFPR porque eu me candidatei na coordenação do meu curso lá na USACH. Eles receberam um aluno da UFPR no meu lugar".

Apesar de parecer que o aumento de confiança não implicaria maior arcabouço normativo, este foi imprescindível por se tratar de universidades públicas de diferentes países na busca de integração. Mesmo assim, pode-se afirmar que a confiança importa mais que a norma, porque a entrada na rede depende de convite pelas universidades-membro e, secundariamente, do cumprimento dos requisitos, conforme ilustra a fala de um dos funcionários da AUGM sobre a entrada da Universidade Federal de Goiás (UFG) na AUGM:

Na minha opinião, creio que com isso perdemos o que é melhor para a AUGM. Por exemplo a Universidade de Goiás entrou para a AUGM concorrendo com a UFRJ. Para a AUGM, seria prioritário que a UFRJ fosse membro, mas entrou a de Goiás por eleição dos reitores brasileiros membros da AUGM, que respondem a outras situações e conjunturas... como nesse momento o Reitor de Goiás era presidente da ANDIFES, respondeu a outra necessidade, mas não era a necessidade da AUGM.

Relembrando a integração de novos membros, a coordenadora de Programas e Projetos da AUGM comenta que, no ano de 2008, uma universidade boliviana não terminou o processo de integração: "se afiliou, mas não participou". Em dezembro de 2010, ingressaram duas universidades bolivianas novas que estão participando e demonstrando interesse. Segundo ela, o que se observa acerca da história e da evolução da organização é que as universidades iniciais continuam sendo universidades importantes na rede, fator que pode ser um elemento que determine ou indique maior ou menor atividade.

Nesse sentido, embora o mapa da rede demonstre densidade e conectividade de $100 \%$ e ausência de centralização, conforme seria o ideal em uma rede organizacional, deve-se levar 
em consideração o tamanho e a localização de cada universidade-membro. A esse respeito, fazse necessário atentar à fala da coordenadora de Programas e Projetos da AUGM, que afirma que hoje as universidades que compõem a AUGM são muito distintas:

[...] algumas mais pequenas, outras de lugares menos urbanos ou mais longe das cidades mais importantes dos países. O nosso grande desafio nos últimos tempos tem sido integrar as universidades de Bolívia, que são universidades novas para nós, que tem uma realidade distinta em relação as da região do Rio de La Plata.

Uma reflexão cabível neste sentido e que também está ligada às dimensões relacional e cognitiva do capital social é de que forma e até que ponto as características culturais distintas em função da distância geográfica influenciam o desenvolvimento da rede organizacional. Infere-se aqui que a dimensão cognitiva do capital social também interfere na configuração da rede organizacional.

Quanto à dimensão informacional, com a modernização das tecnologias, o acesso à comunicação ficou muito mais fácil e rápido, aumentando, assim, a diversidade, a riqueza e o volume de conteúdo trocado entre os membros de uma rede. No caso específico da AUGM, existem três formas de trabalhar a comunicação: interna, externa e intranet. Na rede de comunicação interna tradicional, cada universidade tem um representante (usualmente do setor de Relações Internacionais). A AUGM transmite a informação de uma universidade à outra, para que cada representante a transmita dentro de sua universidade, formando uma rede que, em algum momento, deve seguir um fluxo de comunicação não administrativa. Já a rede de comunicação externa abrange o site da AUGM e o Boletim Informativo, que foi projetado para ser mensal.

A novidade na rede a partir de 2011 são as ferramentas de comunicação entre Delegados Assessores e secretários das universidades-membro via intranet, cujo sistema permite acesso aos dados dos intercambistas, além do acesso a documentos como requerimentos para visto e cartas circulares. Encontra-se em estudo uma metodologia de trabalho na intranet para dar conta dos núcleos e comitês acadêmicos com dois objetivos: divulgar pesquisas e trabalhos, ou seja, criar uma biblioteca pública digital e on-line; e melhorar conexão entre os membros e fazer uma rede de intercambistas.

Ao observar as alterações nas características (indicadores) próprias de cada dimensão do capital social, é possível analisar como estas influenciam a configuração de uma organização em rede desde sua formação até sua maturidade ou institucionalização. Pode ser visualizado, no Quadro 3, de forma resumida e esquemática, o capital social da rede AUGM em suas distintas dimensões, conforme indicadores preestabelecidos ao longo deste trabalho. 


\begin{tabular}{|c|c|c|c|c|}
\hline Capital social & Indicadores & 1991 & 2001 & 2011 \\
\hline $\begin{array}{c}\text { Dimensão Estru- } \\
\text { tural }\end{array}$ & $\begin{array}{l}\text { 1- Tamanho } \\
\text { 2- Densidade/ co- } \\
\text { nectividade } \\
\text { 3- Simetria } \\
\text { 4- Centralização }\end{array}$ & $\begin{array}{c}\text { 1- } 8 \text { membros = pe- } \\
\text { quena } \\
\text { 2- } 60 \% \text { ou 33,6 laços } \\
\text { 3- Simétrica } \\
\text { 4- } 44 \% \text { de grau e } 62 \% \\
\text { de proximidade; Rei- } \\
\text { tor da UDELAR com } \\
\text { maior centralidade }\end{array}$ & $\begin{array}{c}\text { 1- } 15 \text { membros } \\
\text { 2- } 49 \% \text { ou } 103 \text { laços } \\
\text { 3- Simétrica } \\
\text { 4- 54,22\% de grau } \\
\text { e } 40 \% \text { de proxi- } \\
\text { midade; Reitor da } \\
\text { UDELAR e sede da } \\
\text { AUGM com maior } \\
\text { centralidade }\end{array}$ & $\begin{array}{c}\text { 1- } 28 \text { membros } \\
\text { 2- } 100 \% \text { ou } 756 \\
\text { laços } \\
\text { 3- Simétrica } \\
\text { 4- 0\% }\end{array}$ \\
\hline $\begin{array}{c}\text { Dimensão Rela- } \\
\text { cional }\end{array}$ & $\begin{array}{l}\text { 1- Frequência e } \\
\text { estabilidade } \\
\text { 2- Direção e reci- } \\
\text { procidade } \\
\text { 3- Confiança } \\
\text { 4- Normas } \\
\text { 5- Papel do ator }\end{array}$ & $\begin{array}{l}\text { 1- Não tem } \\
\text { 2- Bidirecional e } \\
\text { recíproca (rede simé- } \\
\text { trica) } \\
\text { 3- Existe para come- } \\
\text { çar a rede } \\
\text { 4- Foi estabelecido } \\
\text { para a formalização } \\
\text { da AUGM } \\
\text { 5- Reitor UDELAR } \\
\text { como estrela e por- } \\
\text { teiro - única ligação } \\
\text { entre partes da rede }\end{array}$ & $\begin{array}{c}\text { 1- Aumento de } \\
\text { membros e ativi- } \\
\text { dades } \\
\text { 2- Bidirecional e } \\
\text { recíproca } \\
\text { 3- Existe no convite } \\
\text { de novos membros } \\
\text { 4- Necessária com } \\
\text { o aumento de } \\
\text { membros e ativi- } \\
\text { dades } \\
\text { 5- Reitor da UDE- } \\
\text { LAR e sede da } \\
\text { AUGM como estre- } \\
\text { la e porteiros - li- } \\
\text { gação entre partes } \\
\text { da rede }\end{array}$ & $\begin{array}{l}\text { 1- Existe em função } \\
\text { das atividades da } \\
\text { rede } \\
\text { 2- Bidirecional e } \\
\text { recíproca (rede si- } \\
\text { métrica) } \\
\text { 3- Existe para a rea- } \\
\text { lização de atividades } \\
\text { entre os membros } \\
\text { 4- Necessária com } \\
\text { o grande número } \\
\text { de membros e ativi- } \\
\text { dades } \\
\text { 5- Não há atores } \\
\text { centrais em desta- } \\
\text { que }\end{array}$ \\
\hline $\begin{array}{l}\text { Dimensões Cog- } \\
\text { nitiva e Informa- } \\
\text { cional }\end{array}$ & $\begin{array}{l}\text { 1- Códigos e lin- } \\
\text { guagem } \\
\text { 2- Diversidade, ri- } \\
\text { queza e volume de } \\
\text { informação } \\
\text { 3- Canais/Veículos } \\
\text { de informação }\end{array}$ & $\begin{array}{l}\text { 1- Português e espa- } \\
\text { nhol } \\
\text { 2- Pouca informação } \\
\text { 3- Telefone e carta }\end{array}$ & $\begin{array}{l}\text { 1- Português e es- } \\
\text { panhol } \\
\text { 2- Aumento da in- } \\
\text { formação } \\
\text { 3- Começa o uso } \\
\text { da internet e do } \\
\text { e-mail; ainda se } \\
\text { utilizam telefone e } \\
\text { carta }\end{array}$ & $\begin{array}{l}\text { 1- Português e es- } \\
\text { panhol } \\
\text { 2- Boletim Informa- } \\
\text { tivo; intranet } \\
\text { 3- Internet e e-mail; } \\
\text { ainda se utilizam te- } \\
\text { lefone e carta }\end{array}$ \\
\hline
\end{tabular}

Quadro 3: Análise das dimensões do capital social na AUGM. Fonte: elaborado a partir dos dados da pesquisa.

O Quadro 3 evidencia que, com o passar dos 20 anos, a rede foi absorvendo novos membros e foi descentralizada. Com isso, os laços passaram a permear toda a rede AUGM. Este fato se deve também à frequência e à estabilidade das atividades desenvolvidas em conjunto pelas universidades-membro da organização. Como resultado final, pode-se afirmar que a AUGM, formada em 1991, foi adquirindo maturidade no período de 1992 a 2000 para se consolidar entre 2001 a 2011. Essa consolidação pressupõe uma institucionalização, uma vez que ocorreu uma tipificação das atividades na organização e que os membros se modificaram ao longo tempo, ocasionando um aumento de laços. Isso possibilitou a criação de capital social próprio da organização em rede AUGM.

\section{CONSIDERAÇÕES FINAIS}

No presente estudo, percebe-se que o capital social interpessoal foi inicialmente a base de sustentação da organização em rede em 1991, mantendo sua importância em 2001 e sendo substituído por um capital social organizacional em 2011. Essa afirmação é corroborada pelo fato de que o forte papel da sede da AUGM de catalisadora e fomentadora de laços em 1991 e 2001 foi substituído por uma posição de mediadora e cogestora em 2011. 
Além da dimensão estrutural do capital social suportada pelo formato da organização em rede, as dimensões relacional, cognitiva e informacional contribuem de forma positiva e indispensável para a formação, a evolução e a configuração da Associação das Universidades do Grupo de Montevidéu (AUGM). A dimensão relacional foi mantida ao longo do tempo por meio da reciprocidade entre os membros. A dimensão cognitiva, por sua vez, também não sofreu significativas alterações nesse período, mantendo os pressupostos de integração ao longo do tempo. Já o aspecto informacional destaca-se pela disponibilidade e pelo uso de tecnologias de informação, ausentes em 1991, presentes em 2001 e melhoradas em 2011, como, por exemplo, com a inserção da intranet.

Sendo assim, ao se manter a dimensão relacional e cognitiva, por meio da identificação e das relações de confiança, foi possível estabelecer normas e expectativas para o desenvolvimento das atividades da rede, levando em conta uma mesma linguagem de significados acadêmicos e uma riqueza de informação estabelecida por canais apropriados. Percebe-se, dessa forma, que, em razão de um conjunto de ativos intangíveis, desenvolvido com base nas relações interpessoais mantidas na rede, a AUGM foi institucionalizada tanto nas universidades-membro quanto no ambiente internacional, ampliando seu capital social e coletivo - coletivo sempre no sentido de bem público.

Ressalta-se que o capital social existe nos níveis micro (dos indivíduos) e macro (das organizações e das redes), podendo ser interpessoal, organizacional (na acepção burocrática) e supraorganizacional. Nesse sentido, não se deve imaginar uma transição de um nível para o outro, mas um complexo de interação entre eles.

Sendo assim, para pesquisas futuras, sugere-se aprofundar a questão dos níveis do capital social, pois este carece de teorização e operacionalização como multinível. Por fim, não é possível afirmar se é a rede que cria o capital social ou se é o capital social que cria a rede, porque um influencia o outro, mas um não se restringe ao outro.

\section{REFERENCIAS}

\section{ASOCIACION DE UNIVERSIDADES GRUPO MONTEVIDEO (AUGM) - 15 años de historia, 2006. Disponível em: <www.augm.edu.uy>. Acesso em: 10 nov. 2011.}

BORGATTI, S.P.; EVERETT, M.G.; FREEMAN, L.C. UCINET for Windows: Software for Social Nework Analysis. Boston: Harvard Analytic Technologies, 2002. Disponível em: http:// www.analytictech.com/ucinet/ucinet.htm. Acesso em: 10 nov. 2011.

BOURDIEU, P. The forms of capital. In. : RICHARDSON, J.G. Handbook of theory and research for the sociology of education. New York: Greenwood Press, 1986. p. 241-258.

BURT, R. S. Structural Holes: the social structures of competition. Massachusetts: Harvard University Press, 1992.
COLEMAN, J. S. Social Capital in the Creation of Human Capital. American Journal of Sociology, v. 94, p. S95-S120, 1988.

DIDRIKSSON, A. La autonomia universitária desde su contemporaneidad. Universidades, n. 31, 3- 16, 2006.

GODOI, C. K. et al. Pesquisa Qualitativa em Estudos Organizacionais. São Paulo: Saraiva, 2006.

GRANOVETER, M. The strength of weak ties. American Journal of Sociology, v. 78, n. 6, p. 1360-1380, 1973.

GRANOVETTER, M. Problems of explanation in economic sociology. In: NOHRIA, N.; ECCLES, R. (Eds). Networks and Organizations: Structure, Form and Action. Boston, Mass: Harvard Business School Press, 1992. p. 25-56.

KOKA, B. R.; PRESCOTT, J.S trategic alliances as social capital: A multidimensional view. Strategic Management Journal, v. 23, p. 795816, 2002. 
LIN, N. Social Capital: A Theory of Social Structure and Action. Cambridge: Cambridge University Press, 2001.

MARTELETO, R.M.; SILVA, A.B.O. Redes e Capital Social: o enfoque da informação para o desenvolvimento local. Brasilia, v.33, n.3, p.4149, 2004.

MONGE, P.R. ; CONTRACTOR, N.S. Emergence of communication networks. In F.M. Jablin and L.L. Putnam (Eds.), New handbook of organizational communication (Pp. 440-502). Newbury Park, CA: Sage, 2001.

NAHAPIET, J.; GHOSHAL, S. Social Capital, intellectual capital and the organizational advantage. Academy of Management Review, v.23, n.2, p.242-266, 1998.

PORTES, A. Social Capital: Its Origins and Applications in Modern Sociology. Annual Review of Sociology, n. 24, 1998.

PUTNAM, R. D. Bowling alone: the collapse and revival of American community. New York: Simon \& Schuster, 2000.

SEBASTIÁN,J.Cooperaçãoe Internacionalização das Universidades. Argentina: Editorial Biblos, 2004.

WASSERMAN, S.; FAUST, K. Social Network Analysis: Methods and Applications. Cambridge: Cambridge University Press, 1994. 